\title{
Proton Therapy in the Treatment of Head and Neck Cancer
}

\author{
${ }^{1}$ Evangelia Katsoulakis, ${ }^{2}$ Natalya Chernichenko, ${ }^{3}$ David Schreiber
}

\begin{abstract}
Aim: To examine the value of proton therapy in relation to other treatment modalities in head and neck cancer.

Review: Proton therapy has evolved into more sophisticated and costly intensity-modulated proton therapy and has resulted in even greater dose reduction to normal critical structures at risk as compared with photon therapy. Early clinical studies in head and neck cancers, especially for tumors of the skull base and paranasal sinuses, suggest that proton therapy is excellent in terms of local control and is comparable to intensity-modulated radiation therapy photons but with lower rates of morbidity.
\end{abstract}

Results: There are many potential advantages to radiation therapy with protons. While there are many single institution studies examining the added value of protons to photon therapy, the value of proton therapy must be examined in prospective randomized clinical studies and across many subsites of head and neck cancer. Additional evidence is necessary to guide efficient clinical practice, patient selection, and tumors that are most likely to benefit from this treatment modality and justify proton therapy use given its significant cost.

Keywords: Head and neck cancer, Proton therapy, Radiation therapy.

How to cite this article: Katsoulakis E, Chernichenko N, Schreiber D. Proton Therapy in the Treatment of Head and Neck Cancer. Int J Head Neck Surg 2017;8(2):45-48.

Source of support: Nil

Conflict of interest: None

\section{INTRODUCTION}

\section{Background}

The Food and Drug Administration approved proton therapy utilization as early as $1988 .{ }^{1}$ Over the last decade, there has been a rapid increase in the number of operating proton facilities in the United States, from 2 in 2003 to 22 in $2016 .^{2}$ While proton therapy utilization has continued to rise throughout the cancer community, there

\footnotetext{
${ }^{1,3}$ Radiation Oncologist, ${ }^{2}$ Chief and Assistant Professor

${ }^{1}$ Department of Radiation Oncology, SUNY Downstate Medical Center, Brooklyn, New York, USA

${ }^{2}$ Department of Head and Neck; Department of Otolaryngology SUNY Downstate Medical Center, Brooklyn, New York, USA

${ }^{3}$ Department of Veterans Affairs, New York Harbor Healthcare Brooklyn, New York, USA
}

Corresponding Author: Natalya Chernichenko, Chief and Assistant Professor, Department of Head and Neck; Department of Otolaryngology, SUNY Downstate Medical Center, Brooklyn New York, USA, e-mail: natalya.chernichenko@downstate.edu is an ongoing debate within the cancer community as to whether widespread clinical use is justified given the significant cost. There is a lack of comparative effectiveness data comparing proton to photon therapy and we may be jumping the gun on its use prior before comparative effectiveness data is mature.

Radiation plays a critical role in the treatment of patients with head and neck cancer in the definitive, adjuvant, as well as recurrent salvage settings. Due to the anatomy of the head and neck and the close proximity of the tumor target to normal critical structures at risk, such as optic nerves, orbits, salivary glands, brain, pituitary grand, carotid arteries, reducing radiation toxicity is paramount. The dose distribution with proton therapy limits dose deposition after a finite distance from the Bragg peak and more normal tissue sparing is expected. Therefore, there has been an increased interest in harnessing the unique physical properties of proton therapy in order to dose escalate radiation delivered to the tumor while decreasing dose to normal tissue with the aim of decreasing treatment toxicity. In addition, just as with photon therapy, the development of intensitymodulated proton therapy (IMPT) has enabled enhanced dosimetric optimization. ${ }^{3}$ There are many studies in the development that are assessing the benefit of protons in head and neck cancer. In a study by van der Laan et al, IMPT was superior to intensity-modulated radiation therapy (IMRT) in terms of decreased dose to pharyngeal constrictors, thereby estimating an $8 \%$ decrease in grade II to IV dysphagia. Others have proposed that a reduction in dose to the posterior fossa achievable with IMPT may result in decreased treatment-related fatigue. ${ }^{5}$ However, these dosimetric-based studies have not yet been analyzed to assess whether they do in fact translate to the proposed clinical benefit.

A larger dosimetric advantage with proton therapy use is appreciable in the setting of ipsilateral treatment targets, such as salivary tumors or early tonsillar tumors. ${ }^{6}$ In a study by Romesser et al, ${ }^{7} 41$ patients who underwent ipsilateral RT for major salivary gland cancer or cutaneous squamous cell carcinoma were examined, 56\% treated with IMRT and $44 \%$ with proton beam RT (PBRT). Proton beam therapy had significantly lower rates of grade II or greater acute dysgeusia (5.65 vs 65.2\% p < 0.001), mucositis $(16.7 \%$ vs $52.2 \% \mathrm{p}=0.019)$, and nausea $(11.1 \%$ vs $56.5 \%$ $p=0.003)$. These results are encouraging and authors 
suggest future studies examining late RT-associated morbidity and quality of life (QoL) measures.

In a study by Gunn et al, 80 patients with oropharyngeal cancer treated with IMPT were evaluated and 2-year overall and progression-free survival was 94.5 and $88.6 \%$ respectively. While there were no patients with grade IV or V toxicity, grade III acute toxicity occurred in 23 patients. In another study by Blanchard et al, ${ }^{9}$ patients with oropharyngeal cancer were case matched: 50 patients IMPT vs 100 patients IMRT, with lower rates of severe weight loss and feeding tube placement in the IMPT group and on multivariate analysis, insertion of a $G$ tube during the acute phase was associated with decreased progression-free survival [hazard ratio (HR) $=3.09 ; 95 \%$ confidence interval $(\mathrm{CI}): 1.19-8.00 ; \mathrm{p}=0.02]$ and overall survival (OS) $(\mathrm{HR}=4.96$; 95\% CI: 1.1-23.0; $\mathrm{p}=0.04)$. These findings are compelling and suggest a possible role of protons in decreasing morbidity and associated health care costs and have spurred interest in oropharyngeal cancer and proton therapy.

The majority of the literature in head and neck cancer and proton therapy are single institution studies and include base of skull chordomas ${ }^{10,11}$ or paranasal sinus tumors. ${ }^{12,13}$ In a meta-analysis examining outcomes with protons vs photons in over 43 cohorts of paranasal sinus and nasal cavity carcinoma, at 5 years both OS and disease-free survival (DFS) were significantly higher with the use of charged particle therapy [relative risk (RR) 1.51 $(p=0.0038)$ and RR $1.93(p=0.0003)] .{ }^{14}$ While on longest follow-up there was no significant difference between the two treatment modalities, on subgroup analysis examining protons vs IMRT, there was significantly higher 5 years DFS [RR $1.44(\mathrm{p}=0.045)]$ and locoregional control at longest follow-up [RR $1.26(p=0.011)]$ with proton therapy. The two groups, however, were not well balanced as higher risk histologies were in the photon group and the dose delivered was equivalent. These results are encouraging and emphasize the need for more randomized trials in various head and neck subsites.

In spite of significant advances in initial treatment of head and neck cancers, locoregional recurrences will develop in a significant percentage of patients, which may be managed by surgery or reirradiation. In the largest multi-institutional series on proton reirradiation therapy, 92 patients with recurrent head and neck cancer previously treated with radiation were examined. ${ }^{15}$ The cumulative index of 1 year locoregional failure was $25.1 \%$, while OS was $65.2 \%$. Acute grade 3 toxicity rates were very low and included mucositis (9.9\%), dysphagia (9.1\%), esophagitis (9.1\%), and dermatitis (3.3\%). Late grade 3 toxicity rates were also low, with dermatitis occurring in $8.7 \%$ and dysphagia in $7.1 \%$. These reported toxicities favorably compare with photon reirradiation in which dermatitis is in the range of 13 to $32 \%$ and mucositis 13 to $43 \% .{ }^{16,17}$ Unfortunately, two patients without evidence of disease developed grade $\mathrm{V}$ bleeding, likely due to blood vessel injury. In this study, locoregional control and survival outcomes were substantial, while toxicity was limited as compared with historical studies using photon therapy. The authors emphasize that additional prospective studies are warranted and they plan to prospectively validate the study and include cost-effectiveness data.

Notwithstanding all possible therapeutic gains associated with proton therapy dose distribution, its use in head and neck has been challenged by heterogeneity of volume density, especially sinuses (air gaps, bone) and tumor volume changes and anatomic shifts over the course of treatment. Changes in density and volumes of the course of treatment may adversely impact dose delivery. ${ }^{18}$

The value of proton therapy has been studied in many cancers, such as lung and prostate. In a recent randomized phase III study examining proton (3D) vs photons in locally advanced non-small cell lung cancer, there was no added benefit to proton therapy, and treatment failure rates at 1 year were higher with proton therapy 24.6 vs $15.6 \%{ }^{19}$ While these results are still in abstract form, the outcomes warrant further investigation as primary endpoint of radiation pneumonitis was not met and in fact radiation pneumonitis was numerically worse, with proton therapy $11 \%$ vs IMRT $7.2 \%$. Moreover, there was a trend for worse survival with proton therapy 26.1 vs 29.5 months with photon therapy. In another study on prostate cancer, at 1 year posttreatment, there was no difference in genitourinary toxicity (18.8 vs $17.5 \%$; OR $=1.08,95 \% \mathrm{CI}=0.76-1.54$, $\mathrm{p}=0.66)$. Moreover, there was no statistically significant difference in gastrointestinal toxicity at 6 or 12 months posttreatment. $^{20}$ The lack of clear benefit thus far does not justify the higher cost associated with protons in this patient context. Many agencies have called for evidencebased guidelines to guide clinical practice. The Agency for Health care Research and Quality, ${ }^{21}$ Institute of Medicine, ${ }^{2}$ and the Patient-Centered Outcomes Research Institute ${ }^{22}$ have all called for well-designed, hopefully, randomized studies examining the added value of proton therapy.

In terms of head and neck cancer, the currently open studies are shown in Table 1. A direct comparison of treatment modalities, proton vs photon radiation therapy in head and neck cancer, is NCT01893307. This is a phase II/III randomized trial of IMPT vs IMRT for the treatment of oropharyngeal cancer of the head and neck. The primary outcome of the study assesses the rate and severity of late grade III to V toxicity between IMRT and IMPT with an expected accrual of 360 patients and completion date of 2023.

Indeed, additional randomized studies are required to ascertain the comparative effectiveness of different 
Proton Therapy in the Treatment of Head and Neck Cancer

Table 1: Proton therapy studies of head and neck cancer

\begin{tabular}{|c|c|c|c|c|c|}
\hline Trial number & Study & Outcome & Enrollment & $\begin{array}{l}\text { Start } \\
\text { date }\end{array}$ & $\begin{array}{l}\text { Expected } \\
\text { completion } \\
\text { date }\end{array}$ \\
\hline NCT02923570 & $\begin{array}{l}\text { Phase II study of proton } v s \\
\text { photon beam radiotherapy in the } \\
\text { treatment of head and neck cancer }\end{array}$ & Grade $\geq 2$ acute mucositis & $\begin{array}{l}\text { Unilateral head and } \\
\text { neck ca } 132 \text { patients }\end{array}$ & $10 / 2016$ & $10 / 2021$ \\
\hline NCT01893307 & $\begin{array}{l}\text { Phase II/III randomized trial of } \\
\text { IMPT vs IMRT for the treatment } \\
\text { of oropharyngeal cancer of the } \\
\text { head and neck }\end{array}$ & $\begin{array}{l}\text { Late grade III-V toxicity between } \\
\text { the two groups cumulative late } \\
\text { grade III+ toxicity anytime } 2 \text { years } \\
\text { postcompletion of RT }\end{array}$ & 360 patients & $8 / 2013$ & $8 / 2023$ \\
\hline NCT01627093 & $\begin{array}{l}\text { Observational study prospective } \\
\text { data collection: Proton therapy } \\
\text { for head and neck malignancies }\end{array}$ & $\begin{array}{l}\text { Overall survival analysis of proton } \\
\text { therapy }\end{array}$ & 375 patients & $1 / 2012$ & $1 / 2018$ \\
\hline NCT01973179 & $\begin{array}{l}\text { Reirradiation of recurrent head } \\
\text { and neck cancer }\end{array}$ & $\begin{array}{l}\text { Primary: Late toxicity ( } 2 \text { years) } \\
\text { Secondary: Acute toxicity; } 2 \text { years } \\
\text { local recurrence-free survival; } \\
2 \text { years OS; QoL }\end{array}$ & 50 patients & $7 / 2015$ & $8 / 2023$ \\
\hline NCT02663583 & $\begin{array}{l}\text { IMPT or trans oral robotic } \\
\text { surgery (TORS) for the treatment } \\
\text { of low-risk oropharyngeal } \\
\text { squamous cell }\end{array}$ & $\begin{array}{l}\text { Primary: Functional outcome } \\
\text { using longitudinal wristband } \\
\text { activity monitoring; functional } \\
\text { outcome using patient-reported } \\
\text { outcome measures }\end{array}$ & 44 patients & $1 / 2016$ & $1 / 2018$ \\
\hline NCT02736786 & $\begin{array}{l}\text { A study of mucosal-sparing } \\
\text { proton beam therapy in resected } \\
\text { oropharyngeal tumors }\end{array}$ & $\begin{array}{l}\text { Primary: Local control rate with } \\
\text { protons after resection with TORS }\end{array}$ & $\begin{array}{l}67 \text { patients } \\
\text { pT1-2 N1-3 M0 with } \\
\text { negative margins, } \\
\text { negative extracapsular } \\
\text { extension, negative } \\
\text { lymphovascular space } \\
\text { invasion }\end{array}$ & $3 / 2016$ & $3 / 2020$ \\
\hline NCT01586767 & $\begin{array}{l}\text { Phase II: Intensity-modulated } \\
\text { or proton radiation therapy for } \\
\text { locally advanced sinonasal } \\
\text { malignancy }\end{array}$ & $\begin{array}{l}\text { Primary: } 2 \text { years local control rates } \\
\text { Secondary: } 5 \text { years vision } \\
\text { preservation rates; } 2 \text { years } \\
\text { regional control; } 5 \text { years OS; } \\
5 \text { years QoL; } 5 \text { years tumor } \\
\text { relapse; } 5 \text { years local control; } \\
5 \text { years neurocognitive function }\end{array}$ & 90 patients & $7 / 2011$ & $7 / 2016$ \\
\hline
\end{tabular}

T: Tumor; N: Node; M: Metastasis

radiation types. Moreover, compounding these challenges, the definitions of comparative effectiveness, incremental effectiveness, and cost vary among stakeholders and countries. ${ }^{23}$ Medicare reimbursements for proton beam therapy is estimated two to three times that of IMRT. One proposed suggestion to curb costs until evidence accrues is suggested by Bekelman and Hahn, ${ }^{24}$ wherein payers will reimburse proton therapy at the photon therapy rate provided patients participate in trials that are expected to generate high-quality evidence. This reference pricing model maintains access to proton therapy with the aim of expanding the necessary research needed. The Centers for Medicare and Medicaid Services does not use cost-effectiveness data to make coverage decisions, which contrasts the views of the UK National Institute for Health and Care Excellence, which considers cost per quality-adjusted life-year when making coverage recommendations. ${ }^{23}$ The American Society for Radiation Oncology has addressed proton coverage for head and neck cancer as suitable for coverage with evidence development, if the patient is enrolled in an institutional review board-approved clinical trial or multi-institutional patient registry. ${ }^{25}$

\section{CONCLUSION}

There are many potential advantages to radiation therapy with protons. While there are many single institution studies examining the added value of protons to photon therapy, the value of proton therapy must be examined in prospective randomized clinical studies and across many subsites of head and neck cancer. Additional evidence is necessary to guide efficient clinical practice, patient selection, and tumors that are most likely to benefit from this treatment modality and justify proton therapy use given its significant cost.

\section{REFERENCES}

1. Mitin T, Zietman AL. Promise and pitfalls of heavy-particle therapy. J Clin Oncol 2014 Sep;32(26):2855-2863.

2. Mishra MV, Aggarwal S, Bentzen SM, Knight N, Mehta MP, Regine WF. Establishing evidence-based indications for proton therapy: an overview of current clinical trials. Int J Radiat Oncol Biol Phys 2017 Feb;97(2):228-235. 
3. Lukens JN, Lin A, Hahn SM. Proton therapy for head and neck cancer. Curr Opin Oncol 2015 May;27(3):165-171.

4. van der Laan HP, van de Water TA, van Herpt HE, Christianen ME, Bijl HP, Korevaar EW, Rasch CR, van t Veld AA, van der Schaaf A, Schilstra C, et al. The potential of intensity-modulated proton radiotherapy to reduce swallowing dysfunction in the treatment of head and neck cancer: a planning comparative study. Acta Oncol 2013 Apr;52(3):561-569.

5. Benghiat H, Cashmore J, Williams T, Green S, Hartley A, Sanghera P. Can protons or altered fractionation decrease neurotoxicity after chemoradiation in head and neck cancer? Clin Oncol (R Coll Radiol) 2014 Dec;26(12):762-764.

6. Kandula S, Zhu X, Garden AS, Gillin M, Rosenthal DI, Ang KK, Mohan R, Amin MV, Garcia JA, Wu R, et al. Spotscanning beam proton therapy vsintensity-modulated radiation therapy for ipsilateral head and neck malignancies: a treatment planning comparison. Med Dosim 2013 Winter;38(4): 390-394.

7. Romesser PB, Cahlon O, Scher E, Zhou Y, Berry SL, Rybkin A, Sine KM, Tang S, Sherman EJ, Wong R, et al. Proton beam radiation therapy results in significantly reduced toxicity compared with intensity-modulated radiation therapy for head and neck tumors that require ipsilateral radiation. Radiother Oncol 2016 Feb;118(2):286-292.

8. Gunn GB, Blanchard P, Garden AS, Zhu XR, Fuller CD, Mohamed AS, Morrison WH, Phan J, Beadle BM, Skinner HD, et al. Clinical outcomes and patterns of disease recurrence after intensity modulated proton therapy for oropharyngeal squamous carcinoma. Int J Radiat Oncol Biol Phys 2016 May;95(1):360-367.

9. Blanchard P, Garden AS, Gunn GB, Rosenthal DI, Morrison WH, Hernandez M, Crutison J, Lee JJ, Ye R, Fuller $\mathrm{CD}$, et al. Intensity-modulated proton beam therapy (IMPT) versus intensity-modulated photon therapy (IMRT) for patients with oropharynx cancer - a case matched analysis. Radiother Oncol 2016 Jul;120(1):48-55.

10. Noël G, Feuvret L, Calugaru V, Dhermain F, Mammar H, Haie-Méder C, Ponvert D, Hasboun D, Ferrand R, Nauraye C, et al. Chordomas of the base of the skull and upper cervical spine. One hundred patients irradiated by a 3D conformal technique combining photon and proton beams. Acta Oncol 2005;44(7):700-708.

11. Ares C, Hug EB, Lomax AJ, Bolsi A, Timmermann B, Rutz HP, Schuller JC, Pedroni E, Goitein G. Effectiveness and safety of spot scanning proton radiation therapy for chordomas and chondrosarcomas of the skull base: first long-term report. Int J Radiat Oncol Biol Phys 2009 Nov;75(4):1111-1118.

12. Resto VA, Chan AW, Deschler DG, Lin DT. Extent of surgery in the management of locally advanced sinonasal malignancies. Head Neck 2008 Feb;30(2):222-229.

13. Truong MT, Kamat UR, Liebsch NJ, Curry WT, Lin DT, Barker FG 2nd, Loeffler JS, Chan AW. Proton radiation therapy for primary sphenoid sinus malignancies: treatment outcome and prognostic factors. Head Neck 2009 Oct;31(10):1297-1308.

14. Patel SH, Wang Z, Wong WW, Murad MH, Buckey CR, Mohammed K, Alahdab F, Altayar O, Nabhan M, Schild SE, et al. Charged particle therapy versus photon therapy for paranasal sinus and nasal cavity malignant diseases: a systematic review and meta-analysis. Lancet Oncol 2014 Aug;15(9): 1027-1038.

15. Romesser PB, Cahlon O, Scher ED, Hug EB, Sine K, DeSelm C, Fox JL, Mah D, Garg MK, Han-Chih Chang J, et al. Proton beam reirradiation for recurrent head and neck cancer: multi-institutional report on feasibility and early outcomes. Int J Radiat Oncol Biol Phys 2016 May;95(1):386-395.

16. Lee N, Chan K, Bekelman JE, Zhung J, Mechalakos J, Narayana A, Wolden S, Venkatraman ES, Pfister D, Kraus D, et al. Salvage re-irradiation for recurrent head and neck cancer. Int J Radiat Oncol Biol Phys 2007 Jul;68(3):731-740.

17. Sher DJ, Haddad RI, Norris CM Jr, Posner MR, Wirth LJ, Goguen LA, Annino D, Balboni T, Allen A, Tishler RB. Efficacy and toxicity of reirradiation using intensity-modulated radiotherapy for recurrent or second primary head and neck cancer. Cancer 2010 Oct;116(20):4761-4768.

18. Mendez LC, Moraes FY, Poon I, Marta GN. The management of head and neck tumors with high technology radiation therapy. Expert Rev Anticancer Ther2016;16(1):99-110.

19. Liao ZX LJ, Komaki R, Gomez DR, O'Reilly M, Allen P, Fossella F, Heymach J, Blumenschein GR, Choi N, Delaney T, et al. Bayesian randomized trial comparing intensity modulated radiation therapy versus passively scattered proton therapy for locally advanced non-small cell lung cancer. J Clin Oncol 2016;119:S65.

20. Yu JB, Soulos PR, Herrin J, Cramer LD, Potosky AL, Roberts KB, Gross CP. Proton versus intensity-modulated radiotherapy for prostate cancer: patterns of care and early toxicity. J Natl Cancer Inst 2013 Jan;105(1):25-32.

21. Trikalinos TA, Terasawa T, Ip S, Raman G, Lau J. AHRQ comparative effectiveness technical briefs. In: Particle beam radiation therapies for cancer. Rockville (MD): Agency for Healthcare Research and Quality (US); 2009.

22. PCORI. Research prioritization topic briefs: Topic 13. Chapel Hill: PCORI; 2017 [cited 2017]. Available from: http:// www.pcori.org/sites/default/files/PCORI-Assessment-ofOptions-Topic-Brief-3-of-3-011314.pdf.

23. Weinstein MC. How much are Americans willing to pay for a quality-adjusted life year? Med Care 2008 Apr;46(4):343-345.

24. Bekelman JE, Hahn SM. Reference pricing with evidence development: a way forward for proton therapy. J Clin Oncol 2014 May;32(15):1540-1542.

25. Allen AM, Pawlicki T, Dong L, Fourkal E, Buyyounouski M, Cengel K, Plastaras J, Bucci MK, Yock TI, Bonilla L, et al. An evidence based review of proton beam therapy: the report of ASTRO's emerging technology committee. Radiother Oncol 2012 Apr;103(1):8-11. 